\title{
Title: Acral lentiginous melanoma: clinicopathologic and survival differences according to tumour location.
}

Running title: Acral lentiginous melanoma and location

Authors: Howard, Matthew ${ }^{1,2}$ (MBBS (Hons), BPharm (Hons)), Xie, Charles (MBBS, BMedSci,) ${ }^{3}$, Wee, Edmund $^{4}$ (MBBS (Hons)), Wolfe, Rory (PhD) ${ }^{2}$, McLean, Catriona ${ }^{1,5}$ (FRCPA, MD), Kelly, John W ${ }^{1}$.

(FACD, MD) and Pan, Yan $^{1}$ (MBBS, FACD)

Author ORCID: https://orcid.org/0000-0002-7988-7577

\section{Affiliations:}

1. Victorian Melanoma Service, Alfred Hospital, Melbourne, Victoria, Australia

2. School of Public Health and Preventive Medicine, Monash University, Melbourne, Victoria, Australia

3. Department of Dermatology, Peter MacCallum Cancer Centre, Melbourne, Victoria, Australia

4. Department of Dermatology, St Vincent's Hospital Melbourne

5. Department of Anatomical Pathology, Alfred Hospital, Melbourne, Victoria, Australia

This manuscript nor any of its contents have been presented by the authors

\section{Funding sources:}

Dr Howard was supported by a postgraduate research training program scholarship as part of higher research degree at Monash University from Australian Government funding.

\section{Conflict of interest:}

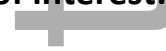

The authors have no conflicts of interest to declare

Corresponding author: Matthew Howard, email: Matthew.david.howard@gmail.com

Postal address: 55 Commercial Rd, Melbourne, Victoria, Australia, 3004, telephone: +61435117162

This is the author manuscript accepted for publication and has undergone full peer review but has not been through the copyediting, typesetting, pagination and proofreading process, which may lead to differences between this version and the Version of Record. Please cite this article as doi: $10.1111 /$ AJD.13310

This article is protected by copyright. All rights reserved 
Word count: 1756 words

Reference count: 33

Table count: 1

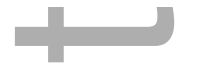

Figure count: 5

\section{Acknowledgements}

We also would like to thank the assistance provided by Ms Karen Scott, Research Database Manager at the Victorian Melanoma Service, the Victorian Cancer Registry and all of the staff at the Victorian Melanoma Service for their support towards this project.

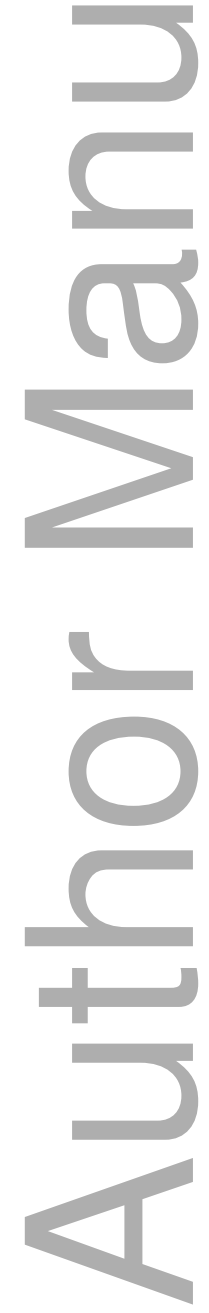

This article is protected by copyright. All rights reserved 
DR. MATTHEW DAVID HOWARD (Orcid ID : 0000-0002-7988-7577)

DR. EDMUND WEE (Orcid ID : 0000-0003-4351-0716)

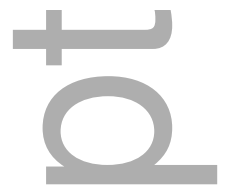

$\square$

Article type : Original Research

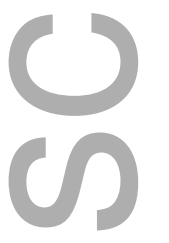

Abstract

Background/Objectives: Acral lentiginous melanoma (ALM) is a melanoma subtype associated with atypical locations on the hands and feet and advanced disease at diagnosis. There is a limited understanding of whether the survival is similar for nail, non-nail, lower limb and upper limb ALM patients. We therefore explored clinicopathologic characteristics and melanoma specific survival (MSS) of ALM patients according to tumour location.

Methods: A prospectively collected cohort study was performed of all primary invasive cutaneous nodular melanomas with known thickness and tumour location reviewed at a tertiary referral centre over 21 years.

Results: 101 ALM patients were reviewed from 1994 until 2016. The majority of cases (82/101) occurred on the feet. Hand ALMs were thicker and more likely to be ulcerated than feet ALMs $(P=0.05$ and 0.02 respectively), however survival was not statistically different between these two groups (univariate HR $0.48 \mathrm{P}=0.11,95 \% \mathrm{Cl} 0.20-1.17$; multivariate $\mathrm{HR} 0.67 \mathrm{P}=0.40,95 \% \mathrm{Cl}$ 0.27-1.69 respectively). Non-nail ALM patients had longer survival when compared to nail ALM on univariate analysis ( $\mathrm{HR} 0.40,95 \% \mathrm{Cl}, 0.17$ to 0.90 ) which was accounted for by Breslow thickness and ulceration (multivariate HR $0.56,95 \% \mathrm{Cl}, 0.24$ to 1.34 ).

Conclusions: The reduced MSS in nail ALM patients was likely due to their greater thickness and ulceration. Although hand ALMs are thicker and more frequently ulcerated, this is likely due to the higher proportion of nail ALMs present in this location.

This article is protected by copyright. All rights reserved 
Keywords: acral lentiginous melanoma, histologic subtype, tumour location, survival, clinicopathologic, ALM, nail melanoma

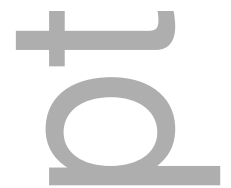

\section{Abbreviations:}

ALM- acral lentiginous melanoma

MSS- melanoma specific survival

HR- Hazard ratio

$\mathrm{Cl}$ - Confidence interval

AJCC- American joint committee on cancer

VMS- Victorian Melanoma Service

NMSC- non-melanoma skin cancer

HPF-high powered field

VCR- Victorian Cancer Registry

MICE- Multiple imputation using chained equations

\section{Introduction}

Acral lentiginous melanoma (ALM) characteristically affects the volar surfaces of the hands and feet as well as the nail apparatus ${ }^{1}$. It is a less frequent subtype in Caucasians than other melanoma subtypes, but ALM comprises a much higher percentage of all melanoma in Hispanic, Asian and African populations where there is a lower proportion of UV related subtypes ${ }^{2-10}$. In keeping with the typical locations affected by ALM, its epidemiology is unusual with a lack of association to either ultraviolet radiation, total non acral or acral naevi counts and distinct mutational profiles compared to other subtypes ${ }^{11-14}$. 
The acral locations diagnosed with ALM have an interesting distribution. The majority of ALM are diagnosed in the lower extremities, where most are located on the plantar sole and relatively few occur in the toenail apparatus ${ }^{5,15-17}$. Conversely, most upper limb ALMs are associated with the fingernail apparatus ${ }^{15,17}$. There is conflicting evidence whether clinicopathologic variables differ between upper and lower limb ALM ${ }^{18}$ and between nail and non-nail $\mathrm{ALM}^{13,19}$. Consequently, it is unclear whether survival differs according to ALM location ${ }^{19}$ and whether clinicopathologic prognostic factors influence this comparison.

The aim of the study therefore was to evaluate the impact of tumour location on ALM survival in greater detail than has previously been possible.

\section{Materials and Methods}

Institutional ethics approval was obtained from the Hospital and University HRECs for this study. All invasive cutaneous primary melanoma cases reviewed the Victorian Melanoma Service (VMS) from the commencement of the service in 1994 until January 2016 with known Breslow thickness and location were included. The VMS is a multidisciplinary tertiary referral service located at the Alfred Hospital in Melbourne. It reviews approximately one quarter of total new diagnoses of melanoma in the Australian state of Victoria.

Clinical features of each patient collected by the reviewing clinician included: age, sex, date of diagnosis (biopsy date) and tumour location coded utilising a body map of 232 areas differentiating anterior from posterior, left from right and midline structures, as developed by the Pigmented Lesion Study Group $)^{20}$. Other clinical features recorded included: clinical hypomelanosis, hair colour, revious history of non-melanoma skin cancer and family history of melanoma. Patients were subsequently examined by reviewing clinicians to determine total naevi count. Independent pathology review of each melanoma case was undertaken by an expert melanoma dermatopathologist. Histologic features that were assessed included: tumour subtype according to World Health Organization guidelines (in order to verify each case was acral lentiginous melanoma $)^{21}$, Breslow thickness, ulceration status, mitotic rate $\left(\mathrm{mm}^{2}\right)$, neurotropism, lymphovascular invasion, satellite metastasis, regression and tumour invading lymphocytes. As mitotic rate was recorded in per 10 high powered field (HPF) prior to 2005, reporting pathologist's conversion factors were utilised to convert to per millimeter squared.

Survival information for all patients in the study was obtained by linkage with the Victorian Cancer Registry (VCR), a population-based cancer registry that collects data on all cancer diagnoses and mortality for residents in the state of Victoria, Australia. Patient vital status was current as of $31^{\text {st }}$ 
December 2015. For patients diagnosed with more than one primary cutaneous melanoma, the melanoma with the greatest Breslow thickness was retained for our analysis ${ }^{22}$

After exclusion of insitu cases ( $n=23$ ALMs), non-registry linked cases ( $n=4$ ALMs), unknown Breslow thickness ( $n=3$ ALMs), non cutaneous melanoma ( $n=4$ for total cohort) and multiple melanomas ( $n=334$ for total cohort), 101 invasive acral lentiginous melanoma cases were available for analysis out of 3570 cutaneous invasive melanoma patients in total (2.8\% of total melanoma cases).

Differences in clinicopathologic data between groups of interest were compared using the Wilcoxon rank tests (for continuous variables) and chi-squared tests (for categorical variables) or fisher exact tests (for categorical variables when values were less than 5). Analysis of MSS for association between ALM tumour locations was performed using Cox proportional hazards models. Given a skewed distribution for Breslow thickness, a log transformation was applied with the transformed version included in models as a continuous variable. Age at diagnosis was dichotomised for analysis at the median age of the total cohort of 65 years. Mitotic rate was categorised into five strata to allow discrimination and create similar strata to observed survival differences in AJCC data ${ }^{22}$ Multiple imputation using chained equations (MICE) method was used to impute values in place of missing data for ulceration(see Table 1 legend for the number of missing values for each variable) ${ }^{23}$. There were no missing values for location, thickness, age, sex and previous history of melanoma. Pre and post imputation diagnostic checks led to assumption of missing at random.

The Nelson-Aalen estimate of cumulative hazard generated from univariate analysis and the censor indicator variable were included in the imputation model ${ }^{24}$. Ten data sets (cycles) with imputed values for each missing value were generated and results of analysis applied to all ten sets were combined according to Rubin's rules ${ }^{25}$. All statistical analyses were performed using Stata (Version 14.3, StataCorp, College Station, TX). Results were considered statistically significant if the P value was less than 0.05 .

\section{Results}

\section{Acral lentiginous melanoma tumour location}

Most cases of ALM were on the feet (82/101 cases, 81\% of ALMs) with 19/101 cases on the hands (19\%, Table 1).There were sixteen fingernail ALM diagnosed on the right hand versus ten on the left hand, with the thumbnail the most common site (11/16 of total fingernail ALM, Figure 1). Palmar ALM was uncommon, with only three cases in a total of 19 hand ALMs. Twenty of 82 ALM of the feet occurred under the toenails, with equal frequency on left and right sides (10 each). Thirty five ALM occurred on the plantar soles. 
Median Breslow thickness and ulceration rates did differ significantly between upper and lower limb ALM $(2.3 \mathrm{~mm}, 1.5 \mathrm{~mm}, \mathrm{P}=0.05$ respectively; with $63 \%$ of upper limb ALM ulcerated, and $34 \%$ of lower limb ALM ulcerated, $P=0.02$ each, Table 1). Sixteen from 23 ALM specific deaths occurred in cases on the feet. The 82 patients with ALM on the foot had longer survival than the 19 patients with ALM on the hand although this did not reach statistical significance (univariate HR $0.48 \mathrm{P}=0.11,95 \%$ confidence interval (CI) 0.20-1.17; multivariate (adjusted for Breslow thickness and ulceration) HR $0.67 \mathrm{P}=0.40,95 \% \mathrm{Cl} 0.27-1.69$ respectively).

Greater median Breslow thickness and rates of ulceration for nail ALM over non-nail ALM appear the likely reason for this survival difference (median Breslow thickness $2.2 \mathrm{~mm}$ and $1.5 \mathrm{~mm}$ respectively; $\mathrm{P}=0.09,19 / 36$ (53\%) nail ALM were ulcerated compared to $21 / 65$ (32\%) non-nail ALM, $\mathrm{P}=0.02$ ). Right-sided nail ALM had a greater median thickness than left-sided nail ALM (3mm versus $1.7 \mathrm{~mm}$, $\mathrm{P}=0.04)$. Melanoma specific survival was compared between patients with nail ALM and those with non-nail ALM. In univariate analysis, non-nail ALM patients had improved survival compared to those with nail apparatus ALM (HR 0.40, P=0.03, 95\% Cl 0.17-0.90). This was accounted for by for adjustment with Breslow thickness and ulceration (multivariate $\mathrm{HR} 0.56, \mathrm{P}=0.19,95 \% \mathrm{Cl} 0.24-1.34$ ).

\section{Discussion}

This study describes survival outcomes of a prospectively collected Australian ALM cohort with respect to location. Patients with nail ALM had worse univariate survival than non-nail ALM. This was due to nail ALM being thicker and more often ulcerated than non-nail ALM. Patients with ALM on the foot had longer survival than the patients with ALM on the hand although this did not reach statistical significance. This may have been due to the higher proportion for fingernail ALM in the upper limb in contrast to the lower limb and therefore also due to more advanced disease observed in nail ALM.

With respect to ALM survival based on upper or lower limb location, a previous study did not demonstrate a significant difference in survival between hand and feet ALM ${ }^{18}$. The hallux and thumbnails were the most common locations for nail ALM in our cohort similar to previous data (Figures $2-3)^{26}$. However, our data were in contrast to the previous suggestion that the right hand is more commonly affected than the left for upper limb ALM ${ }^{19}$. There are varying results on whether ALM is more common on weight bearing portions of the foot prone to trauma ${ }^{19,27,28}$. Out of the 82 ALM of the feet, 34 occurred on weight bearing areas of the foot (Figures 4-5), with another 20 within the toenail apparatus. Cases of dorsal foot melanoma were validated as acral lentiginous melanoma by independent dermatopathologist review, the majority extended from the lateral or 
medial edge of the plantar sole on glabrous skin and all shared lentiginous pattern without evidence of significant solar damage.

Two previous survival comparisons between nail and non-nail ALM were identified in literature: one did not detect a survival difference ${ }^{19}$, another demonstrated reduced multivariate overall survival in patients with hypopigmented nail melanoma, however not all patients were exclusively acral lentiginous subtype ${ }^{29}$. Previous studies have reported higher rates of ulceration in nail ALM, similar to our findings. However we found an increased Breslow thickness ${ }^{19}$ of nail ALM in comparison to non-nail ALM, in contrast to other studies ${ }^{20,48}$. As nail ALM is often misdiagnosed for infection or trauma, delayed diagnosis rather than rapid growth may explain the pathological differences between nail and non-nail ALM $^{30,31}$. Greater thickness in right compared to left sided nail ALM mirrored the findings from another study ${ }^{32}$ and this has been suggested to be due to either more rapid growth or due to greater risk of mechanical stress given high frequency of right hand dominance in the population ${ }^{32}$

The proportion of ALM in our cohort was similar to other Caucasian cohorts reporting ALM incidence between 2-3\% $\%^{4,5,33}$. Predominance of ALM in the feet, women and older patients was also consistent with several previous reports ${ }^{5,9,16}$. Other studies support the finding of the thumb and the hallux as the most common subsites for nail $\mathrm{ALM}^{31}$ and the hand to have a predominance of nail rather than acral ALM ${ }^{15}$.

There were limitations to our study, including potential for referral bias given the tertiary nature of our service. This means patients with difficult to treat sites (ie. Nail ALM) are more likely to have been referred to our institution. Molecular testing was introduced relatively recently hence mutational status was not assessed because it was incomplete for older cases.

Overall, there are distinct differences in clinicopathological features and frequency in locations diagnosed with ALM. Differences in ulceration and potentially thickness between nail and non-nail ALM in our data were observed, which likely accounted for both the univariate decreased MSS of nail ALM patients as well as the difference in hand versus foot ALM MSS that approached significance. Further research is required to establish why nail ALM is diagnosed with advanced features compared to volar ALM.

This article is protected by copyright. All rights reserved 


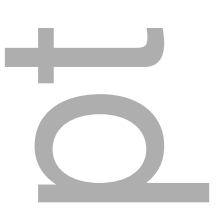

\section{References}

1. Desai A, Ugorji R, Khachemoune A. Acral melanoma foot lesions. Part 1: epidemiology, aetiology, and molecular pathology. Clin Exp Dermatol. 2017;42(8):845-8.

2. Lino-Silva L, Zepeda-Najar C, Salcedo-Hernández R, Martínez-Said H. Acral Lentiginous Melanoma: Survival Analysis of 715 Cases. J Cutan Med Surg [Internet]. 2018.

3. Arrington JH, 3rd, Reed RJ, Ichinose H, Krementz ET. Plantar lentiginous melanoma: a distinctive variant of human cutaneous malignant melanoma. Am J Surg Pathol. 1977;1(2):131-43.

4. Wu X, Eide $M$, King J, Saraiya $M$, Huang $Y$, Wiggins $C$, et al. Racial and ethnic variations in incidence and survival of cutaneous melanoma in the United States, 1999-2006. J Am Acad Dermatol. 2011;65(5 Suppl 1):S26-37.

5. Bradford P, Goldstein A, McMaster M, Tucker M. Acral lentiginous melanoma: incidence and survival patterns in the United States, 1986-2005. Arch Dermatol. 2009;145(4):427-34.

6. Hudson D, Krige J. Melanoma in black South Africans. J Am Coll Surg. 1995;180(1):65-71.

7. Chi Z, Li S, Sheng X, Si L, Cui C, Han M, et al. Clinical presentation, histology, and prognoses of malignant melanoma in ethnic Chinese: a study of 522 consecutive cases. BMC Cancer. 2011;11:85.

8. Roh M, Kim J, Chung K. Treatment and outcomes of melanoma in acral location in Korean patients. Yonsei Med J. 2010;51(4):562-8.

9. Lee H, Chay W, Tang M, Chio M, Tan S. Melanoma: differences between Asian and Caucasian patients. Ann Acad Med Singapore. 2012;41(1):17-20.

10. Pollitt R, Clarke C, Swetter S, Peng D, Zadnick J, Cockburn M. The expanding melanoma burden in California hispanics: Importance of socioeconomic distribution, histologic subtype, and anatomic location. Cancer. 2011;117(1):152-61.

11. Dika E, Veronesi G, Altimari A, Riefolo M, Ravaioli G, Piraccini B, et al. BRAF, KIT, and NRAS Mutations of Acral Melanoma in White Patients. Am J Clin Pathol. 2020.

12. Nagore E, Pereda C, Botella-Estrada R, Requena C, Guillén C. Acral lentiginous melanoma presents distinct clinical profile with high cancer susceptibility. Cancer Causes Control.

2009;20(1):115-9.

This article is protected by copyright. All rights reserved 
13. Phan A, Touzet S, Dalle S, Ronger-Savlé S, Balme B, Thomas L. Acral lentiginous melanoma: histopathological prognostic features of 121 cases. Br J Dermatol. 2007;157(2):311-8.

14. Dika E, Altimari A, Patrizi A, Gruppioni E, Fiorentino M, Piraccini B, et al. KIT, NRAS, and BRAF mutations in nail apparatus melanoma. Pigment Cell Melanoma Res. 2013;26(5):758-60.

15. Kitajima K, Nakamoto Y, Okizuka H, Onishi Y, Senda M, Suganuma N. Accuracy of whole-body FDG-PET/CT for detecting brain metastases from non-central nervous system tumors. Ann Nucl Med. 2008;22(7):595-602.

16. Tas F, Erturk K. Acral Lentiginous Melanoma Is Associated with Certain Poor Prognostic Histopathological Factors but May Not be Correlated with Nodal Involvement, Recurrence, and a Worse Survival. Pathobiology. 2018;85(4):227-31.

17. Durbec F, Martin L, Derancourt C, Grange F. Melanoma of the hand and foot: epidemiological, prognostic and genetic features. A systematic review. Br J Dermatol. 2012;166(4):727-39.

18. Teramoto Y, Keim U, Gesierich A, Schuler G, Fiedler E, Tuting T, et al. Acral lentiginous melanoma: a skin cancer with unfavourable prognostic features. A study of the German central malignant melanoma registry (CMMR) in 2050 patients. Br J Dermatol. 2018;178(2):443-51.

19. Jung $\mathrm{H}$, Kweon S, Lee J, Lee S, Yun S. A clinicopathologic analysis of 177 acral melanomas in Koreans: relevance of spreading pattern and physical stress. JAMA Dermatol. 2013;149(11):1281-8.

20. Clark WH, Jr., Elder DE, Van Horn M. The biologic forms of malignant melanoma. Hum Pathol. 1986;17(5):443-50.

21. Smoller BR. Histologic criteria for diagnosing primary cutaneous malignant melanoma. Mod Pathol. 2006;19(S2):S34-40.

22. Gershenwald JE, Scolyer RA, Thompson JF, Hess KR, Sondak VK, Long GV, et al. Melanoma staging: Evidence-based changes in the American Joint Committee on Cancer eighth edition cancer staging manual. CA Cancer J Clin. 2017;67(6):472-92.

23. Lee KJ, Simpson JA. Introduction to multiple imputation for dealing with missing data. Respirology, 2014;19(2):162-7.

24. White IR, Royston P. Imputing missing covariate values for the Cox model. Stat Med. 2009;28(15):1982-98.

25. Rubin DB. Multiple imputation for nonresponse in surveys. New York: Wiley \& Sons Inc; 1987.

26. Boriani F, O'Leary F, Tohill M, Orlando A. Acral Lentiginous Melanoma - misdiagnosis, referral delay and 5 years specific survival according to site. Eur Rev Med Pharmacol Sci. 2014;18(14):1990-6. 
27. Costello C, Pittelkow M, Mangold A. Acral Melanoma and Mechanical Stress on the Plantar Surface of the Foot. N Engl J Med. 2017;377(4):395-6.

28. Fanti P, Dika E, Misciali C, Vaccari S, Barisani A, Piraccini B, et al. Nail apparatus melanoma: is trauma a coincidence? Is this peculiar tumor a real acral melanoma? Cutan Ocul Toxicol.

2013;32(2):150-3.

29. Lee W, Lee J, Won C, Chang S, Choi J, Moon K, et al. Nail apparatus melanoma: A comparative, clinicoprognostic study of the initial clinical and morphological characteristics of 49 patients. J Am Acad Dermatol. 2015;73(2):213-20.

30. Dika E, Piraccini B, Fanti P. Management and treatment of nail melanoma. G Ital Dermatol Venereol. 2017;152(3):197-202.

31. Dika E, Patrizi A, Fanti P, Chessa M, Reggiani C, Barisani A, et al. The Prognosis of Nail Apparatus Melanoma: 20 Years of Experience from a Single Institute. Dermatology. 2016;232(2):177-

84.

32. Minagawa A, Omodaka T, Koga H, Yokokawa Y, Uhara H, Okuyama R. Nail apparatus melanoma thickness is associated with side and age. Br J Dermatol. 2017;177(3):e65-e6.

33. Markovic S, Erickson L, Rao R, Weenig R, Pockaj B, Bardia A, et al. Malignant melanoma in the 21st century, part 1: epidemiology, risk factors, screening, prevention, and diagnosis. Mayo Clin Proc. 2007;82(3):364-80.

\section{Figures}

Figure 1: Detailed body map demonstrating distribution of acral lentiginous melanoma per anatomical subsite $(n=101)$

Figure 2: a 1.2mm Breslow thickness nail acral lentiginous melanoma

Figure 3: a $6 \mathrm{~mm}$ Breslow thickness nail acral lentiginous melanoma

Figure 4: a 4.8mm Breslow thickness non nail acral lentiginous melanoma

Figure 5: an $8.5 \mathrm{~mm}$ Breslow thickness non nail acral lentiginous melanoma 


\section{Tables}

Table 1: Baseline clinicopathologic characteristics of 101 individuals with invasive acral lentiginous melanomas, $\mathrm{P}$ values for differences in distribution of clinicopathologic characteristics according to location

\begin{tabular}{|c|c|c|c|c|c|c|}
\hline Clinicopathologic factor & $\begin{array}{l}\text { Upper } \\
\operatorname{limb}, n=19\end{array}$ & $\begin{array}{l}\text { Lower } \\
\operatorname{limb}, n=82\end{array}$ & P- value ${ }^{a}$ & $\begin{array}{l}\text { Nail, } \\
\mathrm{n}=36\end{array}$ & $\begin{array}{l}\text { Non-nail, } \\
n=65\end{array}$ & P- value ${ }^{a}$ \\
\hline Female Sex, & $6(31 \%)$ & $50(61 \%)$ & 0.02 & $17(47 \%)$ & $39(60 \%)$ & 0.22 \\
\hline Age, y, median (IQR) & $65(57-75)$ & $\begin{array}{l}67.5(56- \\
79)\end{array}$ & 0.63 & $\begin{array}{l}67(61- \\
75)\end{array}$ & $\begin{array}{l}70(54- \\
80)\end{array}$ & 0.88 \\
\hline $\begin{array}{l}\text { Breslow thickness, mm, } \\
\text { median (IQR) }\end{array}$ & $\begin{array}{l}2.3(1.65- \\
4.2)\end{array}$ & $\begin{array}{l}1.5(0.75- \\
3.0)\end{array}$ & 0.05 & $\begin{array}{l}2.2(1.2- \\
4.1)\end{array}$ & $\begin{array}{l}1.5(0.7- \\
3.3)\end{array}$ & 0.09 \\
\hline Ulceration, $\mathrm{n}(\%)$ & $12(63 \%)$ & $28(34 \%)$ & 0.02 & $19(58 \%)$ & $21(33 \%)$ & 0.02 \\
\hline \multicolumn{3}{|c|}{ Mitotic rate, per $\mathrm{mm}^{2}, \mathrm{n}(\%)$} & \multirow[t]{6}{*}{0.34} & & & \multirow[t]{6}{*}{0.64} \\
\hline$(-)<1$ & $3(20 \%)$ & $23(30.3 \%)$ & & $8(28 \%)$ & $18(29 \%)$ & \\
\hline $1-4$ & $7(47 \%)$ & $40(53 \%)$ & & $13(45 \%)$ & $34(55 \%)$ & \\
\hline $5-9$ & $3(20 \%)$ & $7(9 \%)$ & & $4(14 \%)$ & $6(10 \%)$ & \\
\hline $10-19$ & $1(7 \%)$ & $5(7 \%)$ & & $3(10 \%)$ & $3(5 \%)$ & \\
\hline$>20$ & $1(7 \%)$ & $1(1 \%)$ & & $1(3 \%)$ & $1(1 \%)$ & \\
\hline Regression, $\mathrm{n}(\%)$ & $2(13 \%)$ & $6(8 \%)$ & 0.62 & $4(13 \%)$ & $4(7 \%)$ & 0.44 \\
\hline $\begin{array}{l}\text { Lymphovascular } \\
\text { invasion, } \mathrm{n}(\%)\end{array}$ & $2(13 \%)$ & $7(9 \%)$ & 0.64 & $4(13 \%)$ & $5(8 \%)$ & 0.48 \\
\hline Neurotropism, n (\%) & $2(13 \%)$ & $4(5 \%)$ & 0.26 & $3(10 \%)$ & $3(5 \%)$ & 0.34 \\
\hline $\begin{array}{l}\text { Satellite metastases, } \mathbf{n} \\
\text { (\%) }\end{array}$ & 0 & 0 & & 0 & 0 & \\
\hline \multicolumn{2}{|l|}{ Previous melanoma, $\mathbf{n}(\%)$} & & \multirow[t]{4}{*}{1} & & & \multirow[t]{4}{*}{1} \\
\hline 0 & $17(89 \%)$ & $71(87 \%)$ & & $32(89 \%)$ & $56(86 \%)$ & \\
\hline 1 & $2(11 \%)$ & $10(12 \%)$ & & $4(11 \%)$ & $8(12 \%)$ & \\
\hline$\geq 2$ & 0 & $1(1 \%)$ & & 0 & $1(2 \%)$ & \\
\hline \multicolumn{2}{|c|}{ Previous history NMSC, n (\%) } & & \multirow[t]{2}{*}{1} & & & \multirow[t]{2}{*}{1} \\
\hline 0 & $16(84 \%)$ & $62(82 \%)$ & & $30(86 \%)$ & $48(80 \%)$ & \\
\hline
\end{tabular}

This article is protected by copyright. All rights reserved 


\begin{tabular}{|c|c|c|c|c|c|c|}
\hline 1 & $2(11 \%)$ & $9(12 \%)$ & & $4(11 \%)$ & $7(12 \%)$ & \\
\hline $2-5$ & $1(5 \%)$ & $4(5 \%)$ & & $1(3 \%)$ & $4(7 \%)$ & \\
\hline $6-10$ & 0 & $1(1 \%)$ & & 0 & $1(2 \%)$ & \\
\hline Pre-existing naevus, $\mathrm{n}$ & 0 & $10(13 \%)$ & 0.2 & $31(94 \%)$ & $54(87 \%)$ & 0.49 \\
\hline (\%) & & & & & & \\
\hline $\begin{array}{l}\text { Clinically } \\
\text { hypomelanotic, n (\%) }\end{array}$ & $4(21 \%)$ & $6(7 \%)$ & 0.09 & $2(6 \%)$ & $8(13 \%)$ & 0.74 \\
\hline $\begin{array}{l}\text { Number of family } \\
\text { members with history } \\
\text { of melanoma, } n(\%)\end{array}$ & & & 1 & & & 0.72 \\
\hline & $17(89 \%)$ & $68(83 \%)$ & & $32(89 \%)$ & $53(82 \%)$ & \\
\hline 1 & $2(11 \%)$ & $11(13 \%)$ & & $3(8 \%)$ & $10(15 \%)$ & \\
\hline & 0 & 3 & & $1(3 \%)$ & $2(3 \%)$ & \\
\hline \multicolumn{2}{|c|}{ Tumour invading lymphocytes, $n$ (\%) } & & \multirow[t]{5}{*}{0.05} & & & \multirow[t]{5}{*}{0.02} \\
\hline Absent & $9(60 \%)$ & $40(54 \%)$ & & $18(60 \%)$ & $31(53 \%)$ & \\
\hline Minimal/mild & $4(27 \%)$ & $30(41 \%)$ & & $7(23 \%)$ & $27(46 \%)$ & \\
\hline oderate & 0 & $4(5 \%)$ & & $3(10 \%)$ & $1(2 \%)$ & \\
\hline Severe & $2(13 \%)$ & 0 & & $2(7 \%)$ & 0 & \\
\hline \multicolumn{2}{|c|}{ Previous severe sunburns, $n$ (\%) } & & \multirow[t]{6}{*}{0.22} & & & \multirow[t]{6}{*}{0.67} \\
\hline 0 & $10(53 \%)$ & $34(44 \%)$ & & $18(52 \%)$ & $26(43 \%)$ & \\
\hline $1-5$ & $8(42 \%)$ & $32(42 \%)$ & & $13(37 \%)$ & $27(43 \%)$ & \\
\hline $6-10$ & 0 & 7 (9\%) & & $2(6 \%)$ & $5(8 \%)$ & \\
\hline $10-20$ & 0 & $4(5 \%)$ & & $1(3 \%)$ & $3(5 \%)$ & \\
\hline$>20$ & $1(5 \%)$ & 0 & & $1(3 \%)$ & 0 & \\
\hline \multicolumn{2}{|l|}{ Total naevi count, n (\%) } & & \multirow[t]{5}{*}{0.68} & & & \multirow[t]{5}{*}{0.54} \\
\hline$<<50$ & $11(69 \%)$ & $45(63 \%)$ & & $20(71 \%)$ & $36(60 \%)$ & \\
\hline $50-100$ & $3(19 \%)$ & $12(8 \%)$ & & $3(11 \%)$ & $8(13 \%)$ & \\
\hline $100-200$ & $1(6 \%)$ & $12(17 \%)$ & & $2(7 \%)$ & $11(18 \%)$ & \\
\hline$>200$ & $1(6 \%)$ & $7(10 \%)$ & & $3(11 \%)$ & $5(8 \%)$ & \\
\hline \multicolumn{2}{|l|}{ Eye colour, $n(\%)^{\#}$} & & \multirow[t]{4}{*}{0.55} & & & \multirow[t]{4}{*}{0.58} \\
\hline Blue & $12(63 \%)$ & $32(43 \%)$ & & $17(50 \%)$ & $27(46 \%)$ & \\
\hline Green & $1(5 \%)$ & $8(11 \%)$ & & $2(6 \%)$ & $7(12 \%)$ & \\
\hline Light brown/hazel & $2(11 \%)$ & $15(20 \%)$ & & 8 (24\%) & $9(15 \%)$ & \\
\hline
\end{tabular}




\begin{tabular}{|c|c|c|c|c|c|c|}
\hline Brown & $4(21 \%)$ & $19(26 \%)$ & & $7(21 \%)$ & $16(27 \%)$ & \\
\hline \multicolumn{2}{|l|}{ Hair colour, n (\%) } & & \multirow[t]{6}{*}{0.84} & & & \multirow[t]{6}{*}{0.54} \\
\hline Blonde & $3(16 \%)$ & $10(14 \%)$ & & $4(12 \%)$ & $9(16 \%)$ & \\
\hline Red & 0 & $5(7 \%)$ & & 0 & $5(9 \%)$ & \\
\hline Light brown & $6(32 \%)$ & $22(31 \%)$ & & $11(33 \%)$ & $17(29 \%)$ & \\
\hline Brown & $7(37 \%)$ & $28(39 \%)$ & & $14(42 \%)$ & $21(36 \%)$ & \\
\hline Black & $3(16 \%)$ & $7(10 \%)$ & & $4(12 \%)$ & $6(10 \%)$ & \\
\hline $\begin{array}{r}\text { AJCC }^{22} \text { Breslow } \\
\text { thickness categories } \\
\text { per subtype and } \\
\text { melanoma specific } \\
\text { deaths, n (cases), n } \\
\text { (deaths) }\end{array}$ & & & & & & \\
\hline T1 (s1mm thickness) & $3(16 \%)$ & $28(34 \%)$ & & $8(22 \%)$ & $23(35 \%)$ & \\
\hline $\begin{array}{r}\mathrm{T} 2 \text { (1.01-2mm } \\
\text { thickness) }\end{array}$ & $5(26 \%)$ & $17(21 \%)$ & & $9(25 \%)$ & $13(20 \%)$ & \\
\hline $\begin{array}{r}\text { T3 }(2.01-4 \mathrm{~mm} \\
\text { thickness })\end{array}$ & $6(32 \%)$ & $26(32 \%)$ & & $10(28 \%)$ & $22(34 \%)$ & \\
\hline T4 (>4mm thickness) & $5(26 \%)$ & 11 (13.4\%) & & $9(25 \%)$ & 7 (11\%) & \\
\hline
\end{tabular}

IQR= interquartile range, $\mathrm{ALM}=$ acral lentiginous melanoma, $\mathrm{NMSC}=$ non melanoma skin cancer, $\mathrm{AJCC}=$

a P-value for difference between ALM locations from Wilcoxon rank test (for continuous variables) and chi squared tests/Fisher exact tests (for categorical variables).

Number of missing values, $n$ (\% of observed) for ALM: ulceration 5 (5\%), mitotic rate 10 (9\%), Previous history NMSC 6 (5\%), Previous severe sunburns $5(5 \%)$, eye colour $8(8 \%)$, hair colour $10(10 \%)$, naevi count $13(13 \%)$, satellite $9(9 \%)$, lymphovascular invasion $9(9 \%)$, tumour invading lymphocytes $12(12 \%)$, regression $12(12 \%)$, pre-existing naevus 6 (6\%), neurotropism 11 (11\%). 
Table 1: Baseline clinicopathologic characteristics of 101 individuals with invasive acral lentiginous melanomas, $\mathrm{P}$ values for differences in distribution of clinicopathologic characteristics according to location

\begin{tabular}{|c|c|c|c|c|c|c|}
\hline Clinicopathologic factor & $\begin{array}{l}\text { Upper } \\
\operatorname{limb}, n=19\end{array}$ & $\begin{array}{l}\text { Lower } \\
\operatorname{limb}, n=82\end{array}$ & P-value ${ }^{a}$ & $\begin{array}{l}\text { Nail, } \\
n=36\end{array}$ & $\begin{array}{l}\text { Non-nail, } \\
n=65\end{array}$ & P-value ${ }^{a}$ \\
\hline Female Sex, $\mathrm{n}(\%)$ & $6(31 \%)$ & $50(61 \%)$ & 0.02 & $17(47 \%)$ & $39(60 \%)$ & 0.22 \\
\hline Age, y, median (IQR) & 65 (57-75) & $\begin{array}{l}67.5(56- \\
79)\end{array}$ & 0.63 & $\begin{array}{l}67(61- \\
75)\end{array}$ & $\begin{array}{l}70(54- \\
80)\end{array}$ & 0.88 \\
\hline $\begin{array}{l}\text { Breslow thickness, mm, } \\
\text { median (IQR) }\end{array}$ & $\begin{array}{l}2.3(1.65- \\
4.2)\end{array}$ & $\begin{array}{l}1.5(0.75- \\
3.0)\end{array}$ & 0.05 & $\begin{array}{l}2.2(1.2- \\
4.1)\end{array}$ & $\begin{array}{l}1.5(0.7- \\
3.3)\end{array}$ & 0.09 \\
\hline Ulceration, $\mathrm{n}(\%)$ & $12(63 \%)$ & $28(34 \%)$ & 0.02 & $19(58 \%)$ & $21(33 \%)$ & 0.02 \\
\hline \multicolumn{3}{|c|}{ Mitotic rate, per $\mathrm{mm}^{2}, \mathrm{n}(\%)$} & \multirow[t]{6}{*}{0.34} & & & \multirow[t]{6}{*}{0.64} \\
\hline$<<1$ & $3(20 \%)$ & $23(30.3 \%)$ & & $8(28 \%)$ & $18(29 \%)$ & \\
\hline $1-4$ & $7(47 \%)$ & $40(53 \%)$ & & $13(45 \%)$ & $34(55 \%)$ & \\
\hline $5-9$ & $3(20 \%)$ & $7(9 \%)$ & & $4(14 \%)$ & $6(10 \%)$ & \\
\hline $10-19$ & $1(7 \%)$ & $5(7 \%)$ & & $3(10 \%)$ & $3(5 \%)$ & \\
\hline$>20$ & $1(7 \%)$ & $1(1 \%)$ & & $1(3 \%)$ & $1(1 \%)$ & \\
\hline Regression, $n(\%)$ & $2(13 \%)$ & $6(8 \%)$ & 0.62 & $4(13 \%)$ & $4(7 \%)$ & 0.44 \\
\hline $\begin{array}{l}\text { Lymphovascular } \\
\text { invasion, } \mathrm{n}(\%)\end{array}$ & $2(13 \%)$ & 7 (9\%) & 0.64 & $4(13 \%)$ & $5(8 \%)$ & 0.48 \\
\hline Neurotropism, n (\%) & $2(13 \%)$ & $4(5 \%)$ & 0.26 & $3(10 \%)$ & $3(5 \%)$ & 0.34 \\
\hline $\begin{array}{l}\text { Satellite metastases, } \mathbf{n} \\
\text { (\%) }\end{array}$ & 0 & 0 & & 0 & 0 & \\
\hline \multicolumn{2}{|l|}{ Previous melanoma, $\mathrm{n}(\%)$} & & \multirow[t]{4}{*}{1} & & & \multirow[t]{4}{*}{1} \\
\hline 0 & $17(89 \%)$ & $71(87 \%)$ & & 32 (89\%) & 56 (86\%) & \\
\hline 1 & 2 (11\%) & $10(12 \%)$ & & 4 (11\%) & 8 (12\%) & \\
\hline$\geq 2$ & 0 & $1(1 \%)$ & & 0 & $1(2 \%)$ & \\
\hline \multicolumn{2}{|c|}{ Previous history NMSC, $\mathrm{n}(\%)$} & & \multirow[t]{5}{*}{1} & & & \multirow[t]{5}{*}{1} \\
\hline 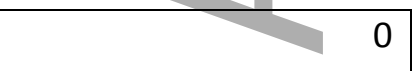 & $16(84 \%)$ & $62(82 \%)$ & & $30(86 \%)$ & $48(80 \%)$ & \\
\hline 1 & $2(11 \%)$ & $9(12 \%)$ & & $4(11 \%)$ & $7(12 \%)$ & \\
\hline $2-5$ & $1(5 \%)$ & $4(5 \%)$ & & $1(3 \%)$ & $4(7 \%)$ & \\
\hline $6-10$ & 0 & $1(1 \%)$ & & 0 & $1(2 \%)$ & \\
\hline
\end{tabular}




\begin{tabular}{|c|c|c|c|c|c|c|}
\hline $\begin{array}{l}\text { Pre-existing naevus, } n \\
\text { (\%) }\end{array}$ & 0 & $10(13 \%)$ & 0.2 & $31(94 \%)$ & $54(87 \%)$ & 0.49 \\
\hline $\begin{array}{l}\text { Clinically } \\
\text { hypomelanotic, n (\%) }\end{array}$ & $4(21 \%)$ & $6(7 \%)$ & 0.09 & $2(6 \%)$ & $8(13 \%)$ & 0.74 \\
\hline $\begin{array}{l}\text { Number of family } \\
\text { members with history } \\
\text { of melanoma, } n(\%)\end{array}$ & & & 1 & & & 0.72 \\
\hline 0 & $17(89 \%)$ & $68(83 \%)$ & & $32(89 \%)$ & $53(82 \%)$ & \\
\hline 1 & $2(11 \%)$ & $11(13 \%)$ & & $3(8 \%)$ & $10(15 \%)$ & \\
\hline$\geq 2$ & 0 & 3 & & $1(3 \%)$ & $2(3 \%)$ & \\
\hline \multicolumn{2}{|c|}{ Tumour invading lymphocytes, $n$ (\%) } & & \multirow[t]{5}{*}{0.05} & & & \multirow[t]{5}{*}{0.02} \\
\hline Absent & $9(60 \%)$ & 40 (54\%) & & $18(60 \%)$ & $31(53 \%)$ & \\
\hline Minimal/mild & $4(27 \%)$ & $30(41 \%)$ & & $7(23 \%)$ & $27(46 \%)$ & \\
\hline Moderate & 0 & $4(5 \%)$ & & $3(10 \%)$ & $1(2 \%)$ & \\
\hline Severe & $2(13 \%)$ & 0 & & $2(7 \%)$ & 0 & \\
\hline \multicolumn{2}{|c|}{ Previous severe sunburns, $\mathrm{n}(\%)$} & & \multirow[t]{6}{*}{0.22} & & & \multirow[t]{6}{*}{0.67} \\
\hline 0 & $10(53 \%)$ & $34(44 \%)$ & & $18(52 \%)$ & $26(43 \%)$ & \\
\hline $1-5$ & $8(42 \%)$ & $32(42 \%)$ & & $13(37 \%)$ & $27(43 \%)$ & \\
\hline & 0 & 7 (9\%) & & $2(6 \%)$ & $5(8 \%)$ & \\
\hline $10-20$ & 0 & $4(5 \%)$ & & $1(3 \%)$ & $3(5 \%)$ & \\
\hline$>20$ & $1(5 \%)$ & 0 & & $1(3 \%)$ & 0 & \\
\hline \multicolumn{2}{|l|}{ Total naevi count, $\mathrm{n}(\%)$} & & \multirow[t]{5}{*}{0.68} & & & \multirow[t]{5}{*}{0.54} \\
\hline$<50$ & $11(69 \%)$ & $45(63 \%)$ & & $20(71 \%)$ & $36(60 \%)$ & \\
\hline $50-100$ & $3(19 \%)$ & $12(8 \%)$ & & $3(11 \%)$ & $8(13 \%)$ & \\
\hline $100-200$ & $1(6 \%)$ & $12(17 \%)$ & & $2(7 \%)$ & $11(18 \%)$ & \\
\hline$>200$ & $1(6 \%)$ & $7(10 \%)$ & & $3(11 \%)$ & $5(8 \%)$ & \\
\hline \multicolumn{2}{|l|}{ Eye colour, $n(\%)^{\#}$} & & \multirow[t]{5}{*}{0.55} & & & \multirow[t]{5}{*}{0.58} \\
\hline Blue & $12(63 \%)$ & $32(43 \%)$ & & $17(50 \%)$ & $27(46 \%)$ & \\
\hline Green & $1(5 \%)$ & $8(11 \%)$ & & $2(6 \%)$ & $7(12 \%)$ & \\
\hline Light brown/hazel & $2(11 \%)$ & $15(20 \%)$ & & $8(24 \%)$ & $9(15 \%)$ & \\
\hline Brown & $4(21 \%)$ & $19(26 \%)$ & & $7(21 \%)$ & $16(27 \%)$ & \\
\hline \multicolumn{2}{|l|}{ Hair colour, $\mathrm{n}(\%)$} & & \multirow[t]{2}{*}{0.84} & & & \multirow[t]{2}{*}{0.54} \\
\hline Blonde & $3(16 \%)$ & $10(14 \%)$ & & $4(12 \%)$ & $9(16 \%)$ & \\
\hline
\end{tabular}




\begin{tabular}{|c|c|c|c|c|}
\hline Red & 0 & $5(7 \%)$ & 0 & $5(9 \%)$ \\
\hline Light brown & $6(32 \%)$ & $22(31 \%)$ & $11(33 \%)$ & 17 (29\%) \\
\hline Brown & $7(37 \%)$ & $28(39 \%)$ & $14(42 \%)$ & $21(36 \%)$ \\
\hline Black & $3(16 \%)$ & $7(10 \%)$ & $4(12 \%)$ & $6(10 \%)$ \\
\hline $\begin{array}{r}\operatorname{AJCC}^{20} \text { Breslow } \\
\text { thickness categories } \\
\text { per subtype and } \\
\text { melanoma specific } \\
\text { deaths, n (cases), } n \\
\text { (deaths) }\end{array}$ & & & & \\
\hline $\mathrm{T} 1$ ( $\leq 1 \mathrm{~mm}$ thickness) & $3(16 \%)$ & $28(34 \%)$ & $8(22 \%)$ & $23(35 \%)$ \\
\hline $\begin{array}{c}\mathrm{T} 2 \text { (1.01-2mm } \\
\text { thickness) }\end{array}$ & $5(26 \%)$ & $17(21 \%)$ & $9(25 \%)$ & $13(20 \%)$ \\
\hline $\begin{array}{r}\mathrm{T} 3(2.01-4 \mathrm{~mm} \\
\text { thickness })\end{array}$ & $6(32 \%)$ & $26(32 \%)$ & $10(28 \%)$ & $22(34 \%)$ \\
\hline $\mathrm{T} 4$ (>4mm thickness) & $5(26 \%)$ & $11(13.4 \%)$ & $9(25 \%)$ & $7(11 \%)$ \\
\hline
\end{tabular}

IQR= interquartile range, $\mathrm{ALM}=$ acral lentiginous melanoma, NMSC= non melanoma skin cancer, $\mathrm{AJCC}=$

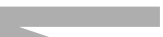

a P-value for difference between ALM locations from Wilcoxon rank test (for continuous variables) and chi squared tests/Fisher exact tests (for categorical variables).

Number of missing values, $\mathrm{n}$ (\% of observed) for ALM: ulceration 5 (5\%), mitotic rate 10 (9\%), Previous history NMSC 6 (5\%), Previous severe sunburns $5(5 \%)$, eye colour $8(8 \%)$, hair colour $10(10 \%)$, naevi count $13(13 \%)$, satellite $9(9 \%)$, lymphovascular invasion $9(9 \%)$, tumour invading lymphocytes $12(12 \%)$, regression $12(12 \%)$, pre-existing naevus 6 (6\%), neurotropism 11 (11\%). 


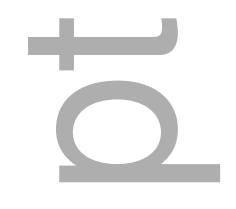

$\square$
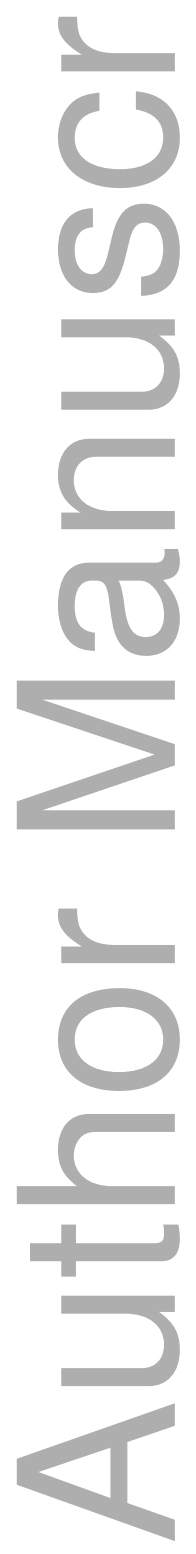

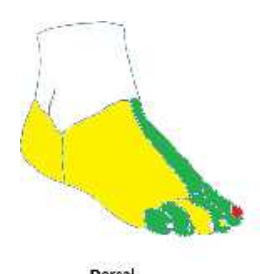

Dorsal
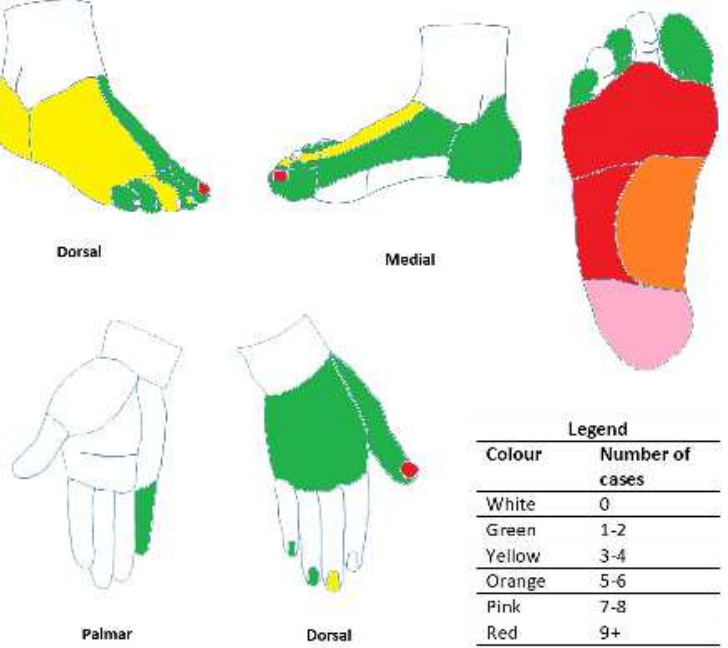

ajd_13310_f1.jpg 

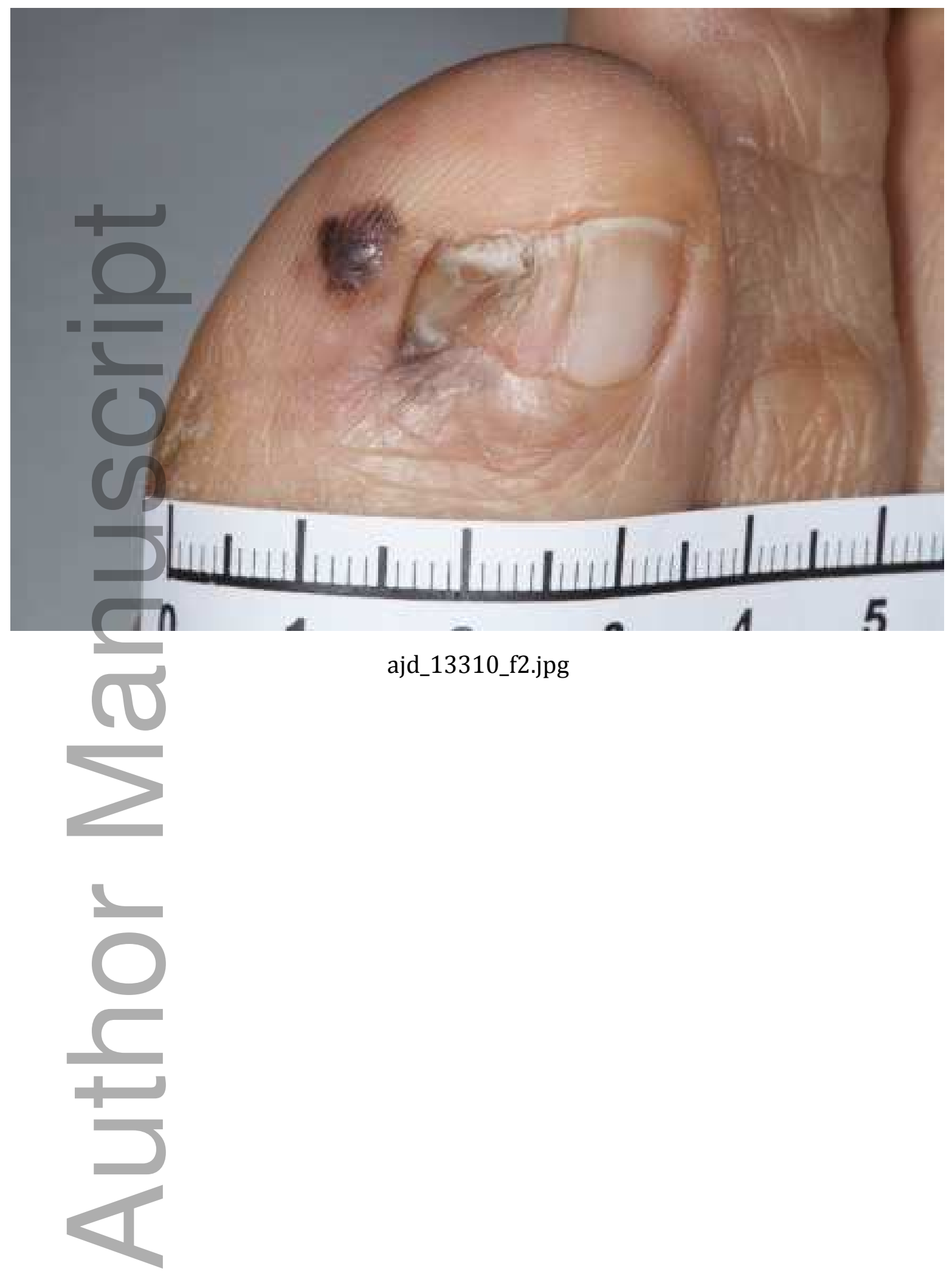

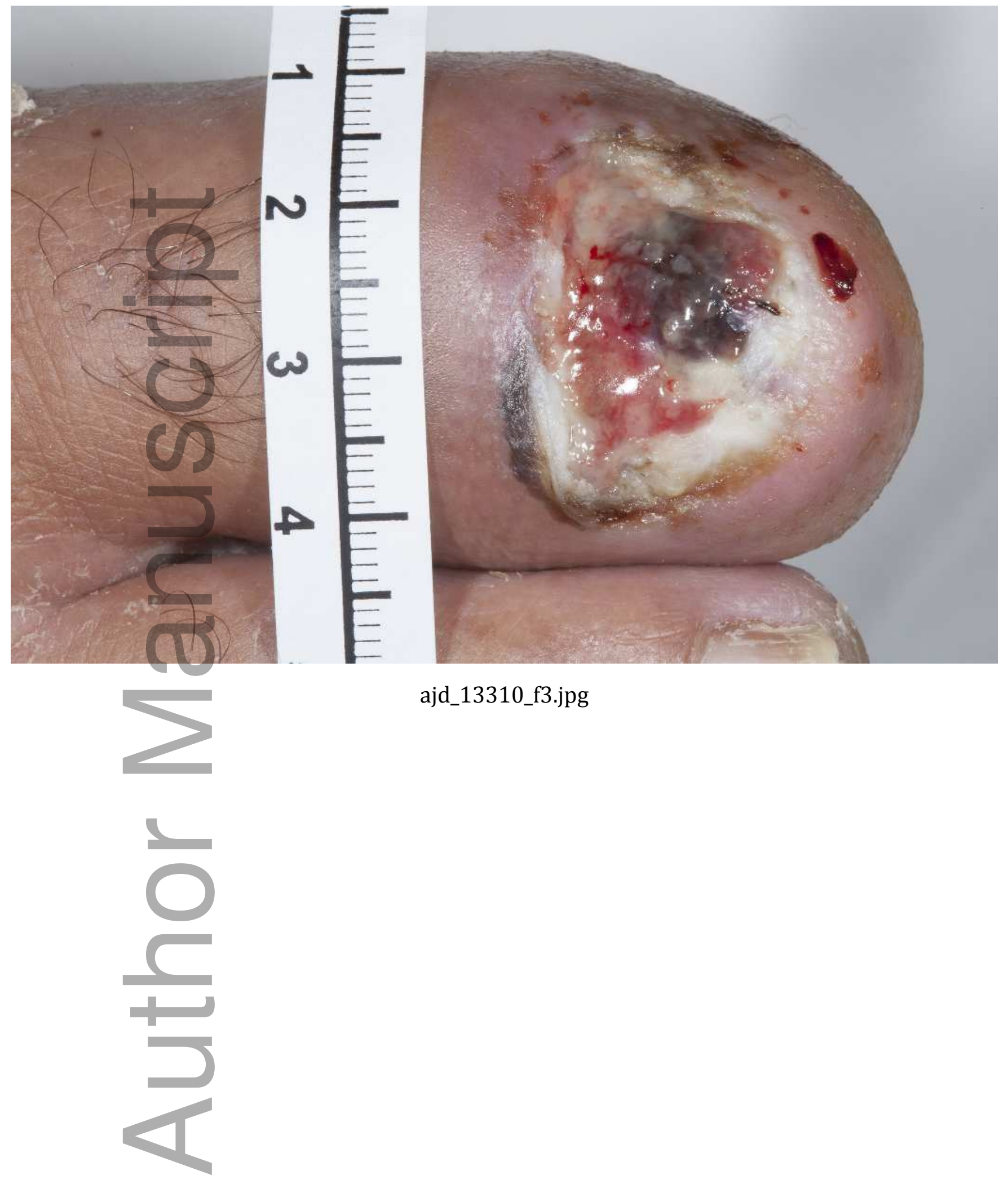

This article is protected by copyright. All rights reserved 


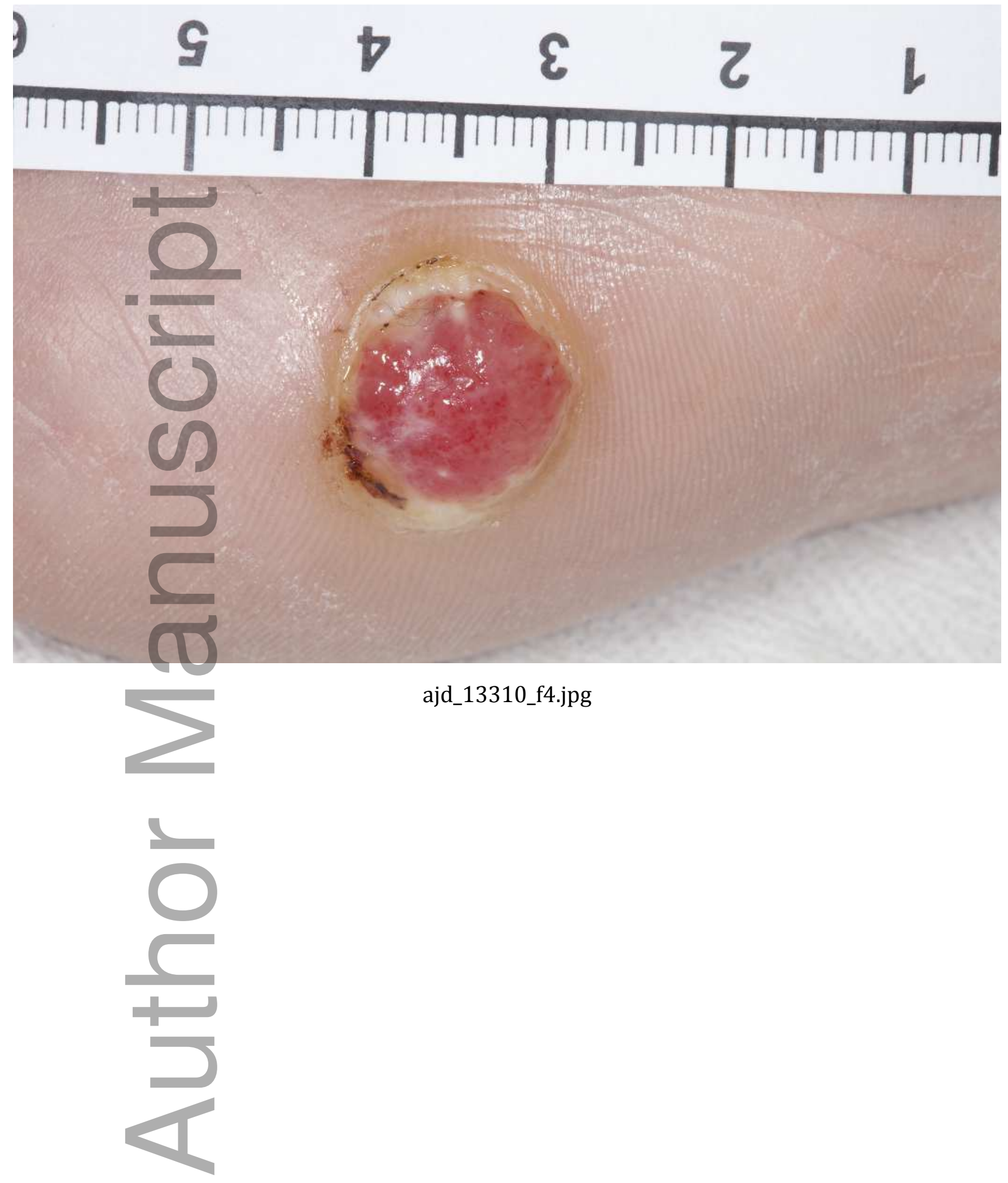

This article is protected by copyright. All rights reserved 


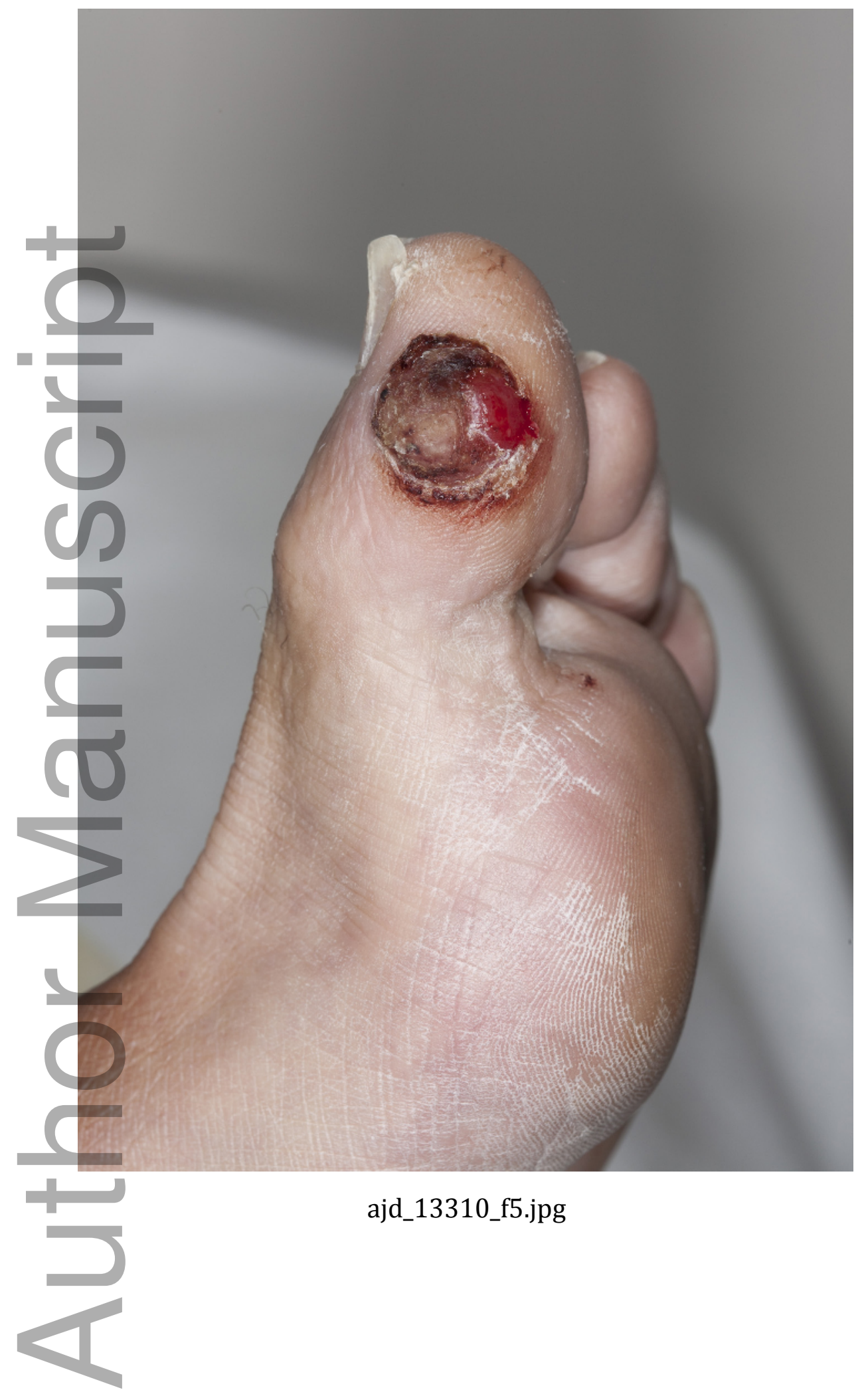

This article is protected by copyright. All rights reserved 


\section{University Library}

\section{- M M N E R VA A gateway to Melbourne's research publications}

Minerva Access is the Institutional Repository of The University of Melbourne

Author/s:

Howard, M;Xie, C;Wee, E;Wolfe, R;McLean, C;Kelly, JW;Pan, Y

Title:

Acral lentiginous melanoma: Clinicopathologic and survival differences according to tumour location

Date:

2020-05-03

Citation:

Howard, M., Xie, C., Wee, E., Wolfe, R., McLean, C., Kelly, J. W. \& Pan, Y. (2020). Acral lentiginous melanoma: Clinicopathologic and survival differences according to tumour location. AUSTRALASIAN JOURNAL OF DERMATOLOGY, 61 (4), pp.312-317. https:// doi.org/10.1111/ajd.13310.

Persistent Link:

http://hdl.handle.net/11343/275710 